\title{
Retroperitoneal Single-port Donor Nephrectomy through Lumbotomy Incision: An Experience of 30 Cases
}

\author{
Navdeep Singh ${ }^{1}$, Deepesh B Kenwar ${ }^{2}$, Sarbpreet Singh ${ }^{3}$, Soham Dasgupta ${ }^{4}$, Kunal Kapoor ${ }^{5}$, Sandeep Kumar ${ }^{6}$, Ashish Sharma ${ }^{7}$
}

\begin{abstract}
Introduction: Over the years, laparoscopic donor nephrectomy (LDN) has evolved as a preferred alternative to open-donor nephrectomy (ODN). Laparoscopic donor nephrectomy can be performed either by transperitoneal or retroperitoneal route. Retroperitoneoscopic live donor nephrectomy (RPLDN) results in less analgesic requirement, decreased hospital stay, and better cosmetic acceptance by the donors. Lumbotomy incision has been thought to be an ideal approach without any muscle being cut but is limited by the amount of space in open surgery.

Materials and methods: Between November 2014 and September 2016, 350 donor nephrectomies were performed at our department. All the surgeries were performed by a single surgeon. Thirty patients consented for translumbar RPLDN out of the 82 donor nephrectomies assigned to that particular surgeon. Visual analog scale (VAS) was used to evaluate the severity of pain on postoperative day (POD)0 and POD1.

Results: Mean age of donors was $44.7 \pm 11.4$ years, M:F ratio 9:21. Average duration of surgery was $170.33 \pm 52$ minutes. Four patients (13.3\%) had double renal arteries and one patient had double renal vein. In one patient, retrieval was performed by an open approach. No patient had surgical site infection. Most patients $(28 / 30)$ had a VAS score of $<4$, and did not require any additional analgesics beyond POD0.

Conclusion: Single-site translumbar RPLDN is a feasible alternative approach to the donor surgery.

Keywords: Laparoscopic, Lumbotomy, Retroperitoneal, Single port.

World Journal of Laparoscopic Surgery (2020): 10.5005/jp-journals-10033-1399
\end{abstract}

\section{INTRODUCTION}

Renal transplantation is the preferred treatment for patients with end-stage renal failure.' Outcomes after transplantation are superior with the use of live-donor kidneys as compared with those from deceased donors but require a healthy person to undergo an invasive procedure. ${ }^{2} \mathrm{~A}$ lot of progress has been made in the recent years to minimize the discomforts associated with donor nephrectomy. Laparoscopic donor nephrectomy (LDN) was first introduced by Ratner et al in 1995 to reduce morbidity associated with the open procedure which was the gold standard for kidney retrieval from living donors at that time. ${ }^{3}$ Over the years, LDN has evolved as a preferred alternative to open-donor nephrectomy $(\mathrm{ODN})$ as the latter procedure results in a protracted convalescence ${ }^{4}$ and has a high incidence wound-related morbidity. ${ }^{5}$ Both a recent meta-analysis ${ }^{6}$ and systematic review ${ }^{7}$ have suggested that LDN results in fewer complications, shorter hospital stay, and faster return to work compared with ODN. Laparoscopic donor nephrectomy can be performed either by transperitoneal or retroperitoneal route. The transperitoneal route of performing donor nephrectomy has been classically described as it provides a larger working space but the retroperitoneal procedure has the advantages of no risk to intra-abdominal organs and direct access to the renal artery/vein. ${ }^{8-10}$ Retroperitoneoscopic live donor nephrectomy (RPLDN) results in less analgesic requirement, decreased stay, and better cosmetic acceptance by the donors. ${ }^{11-14}$ But it has the disadvantage of a muscle cutting/splitting incision for the retrieval of donor kidney in addition to the multiple ports. Lumbotomy incision has been thought to be an ideal approach to reach kidneys without any muscle being cut but is limited by the amount of space in open surgery. A single-port RPLDN performed through lumbotomy incision can provide a nearly ideal approach to donor kidney. Single-site surgeries have been shown to further hasten the recovery after surgery in a number of procedures

\footnotetext{
${ }^{1-7}$ Department of Renal Transplant Surgery, Postgraduate Institute of Medical Education and Research, Chandigarh, India
}

Corresponding Author: Ashish Sharma, Department of Renal Transplant Surgery, Postgraduate Institute of Medical Education and Research, Chandigarh, India, Phone: +91 99142 02301, e-mail: ashishpgi@gmail.com

How to cite this article: Singh N, Kenwar DB, Singh $\mathrm{S}$, et al. Retroperitoneal Single-port Donor Nephrectomy through Lumbotomy Incision: An Experience of 30 Cases. World J Lap Surg 2020;13(2):61-64. Source of support: Nil

Conflict of interest: None

including donor nephrectomy as they reduce the pain associated with the procedure. There have been limited successful reports of retroperitoneoscopic laparoendoscopic single-site nephrectomy (LESS). ${ }^{15}$ However, the present study provides the first experience in the literature of performing a single-port RPLDN through lumbotomy incision.

\section{Materials and Methods}

\section{Donors}

\section{Selection Criteria}

Between November 2014 and September 2016, 350 donor nephrectomies were performed in our department. Preoperative donor evaluation included medical, surgical, and psychosocial suitability for live kidney donation. Renal imaging like renal angiography and differential renal function scan was performed in each patient. Patients with body mass index (BMI) of $>30$ were not considered for RPLDN for the initial experience. No patient had history of any previous retroperitoneal surgery. All the patients received cefazolin $1 \mathrm{~g} 30$ minutes before the start of the procedure. 
All the surgeries were performed by a single surgeon to eliminate the learning curve bias. Thirty patients consented for translumbar RPLDN out of the 82 donor nephrectomies assigned to that particular surgeon. Patients were explained about the risks/benefits associated with single-port retroperitoneal donor nephrectomy through lumbotomy incision. In postoperative period, all patients were administered tramadol thrice daily and then as required. Visual analog scale (VAS) was used to evaluate the severity of pain on postoperative day (POD)0 and POD1.

The study was approved by the Institutional Ethics Committee.

\section{Single-port Retroperitoneal Translumbar Donor Nephrectomy}

Patients were placed in full lateral position and retroperitoneum accessed with a non-muscle cutting approach. ${ }^{16}$ Once the retroperitoneum was entered, Gerota's fascia was opened as far as possible and lower pole of kidney is reached. Dissection was carried out anterior to psoas till ureter and gonadal vein were identified in the retroperitoneal fat.

An Alexis wound retractor was applied to the incision with a sterile surgical glove rolled over the inner ring of the retractor, so that the fingers project out of the outer ring of the Alexis wound retractor, creating an airtight retroperitoneal compartment. Three fingers of the glove were used to insert one $10 \mathrm{~mm}$ camera port, one $10 \mathrm{~mm}$ working port, and one $5 \mathrm{~mm}$ working port and pneumoretroperitoneum obtained.

Further dissection was carried out laparoscopically. Ureter was lifted off the retroperitoneal tissues and gonadal vein was dissected till its drainage into renal vein avoiding injury to the ureter and its adventitia and ligated. Gonadal artery if encountered was also ligated. As one reached renal hilum, pulsations of renal artery could be seen and lumbar vein was visualized in front of the artery. Lumbar vein was controlled after which renal artery was seen which was dissected till its origin. After that, tissue around the renal vein was dissected and adrenal vein was identified.

At this stage, lower pole of the kidney was separated from the peritoneum when the kidney which was hanging from the peritoneum started to fall down. Dissection was carried out on the surface of kidney to free it from the surround fat till renal vein was seen anteriorly. Adrenal vein was identified and divided, adrenal gland was dissected and separated from the upper pole of the kidney and left in situ.

Ureter was divided once the kidney and renal vessels were free.

Renal artery and renal vein were separately ligated with two Hemolok clips each as is the usual practice at our center and cut with scissors. Kidney was retrieved into the Alexis wound retractor, and taken out with the retractor.

\section{Results (Table 1)}

Mean age of donors was $44.7 \pm 11.4$ years, majority of the donors were females (M:F 9:21) as is usual trend at our center. Average duration of surgery was $170.33 \pm 52$ minutes, the duration of surgery decreased with increasing experience. Majority of nephrectomies were left sided (LT:RT 26:4).

Four patients (13.3\%) had double renal arteries and one patient had double renal vein. In one patient, retrieval was performed by an open approach after extending the upper part of the incision. This patient had bleeding from avulsion of a small tributary at the base of right renal vein after completion

\begin{tabular}{ll} 
Table 1: Results \\
\hline Mean age (years) & $44.7 \pm 11.4$ \\
M:F & $9: 21$ \\
BMI $\left(\mathrm{kg} / \mathrm{m}^{2}\right)$ & $21.72 \pm 3.57$ \\
Side $(\mathrm{LT}: \mathrm{RT})$ & $26: 4$ \\
Duration (minutes) & $170.3 \pm 52$ \\
WIT (minutes) & $4.71 \pm 1.2$ \\
Kidney wt (g) & $131.6 \pm 25.5$ \\
Analgesic requirement $(\mathrm{mg})$ & $370 \pm 105$ \\
VAS POD0 & $4.83 \pm 1.73$ \\
VAS POD1 & $3.0 \pm 1.23$ \\
Hospital stay (days) & $2.6 \pm 0.6$ \\
\hline
\end{tabular}

of dissection. No blood transfusion was required in any patient. Peritoneum was breached in three patients but the peritoneal rent was closed after removing the Alexis port and surgery was completed retroperitoneally. No patient had surgical site infection and none had postoperative hernia or bulge at operative site till the last follow-up. Additional $5 \mathrm{~mm}$ port for retraction was required in the two of the first three cases, but subsequent cases were completed without any additional port. Most patients $(28 / 30)$ had a VAS score of $<4$, and did not require any additional analgesics beyond POD0. Patients were started orally on the same day and could ambulate comfortably on the next day.

\section{Discussion}

The first experience of laparoscopic nephrectomy using a single incision was reported in three patients in $2007 .{ }^{17}$ The attractiveness of single-site approach later led to many reports of living donor nephrectomies via LESS surgery. ${ }^{18-20}$ All these were performed using the transperitoneal approach in comparison to the traditional retroperitoneal route for ODN. Most reports of serious complications following LDN are related to the transperitoneal approach causing bowel/visceral injuries or intestinal obstruction. Therefore, an ideal approach to the donor surgery should be a retroperitoneal approach. A non-muscle cutting single-site incision will not only avoid immediate and long-term intraperitoneal complications but also reduce pain associated with the operation. With this in mind, lumbotomy approach was used to perform the single-site nephrectomy in the living donors at our center.

As hypothesized, the main benefit of this approach in our experience was early convalescence. This was possible as the approach through the lumbar fascia avoids muscle cutting or splitting resulting in less postoperative pain, which impacts analgesic requirements and the hospital stay. Single-site surgery has been shown to be less painful than multiple ports approach for donor nephrectomy in a recent Cochrane review as well. ${ }^{21}$ Shoulder pain due to irritation of diaphragm by carbon dioxide gas was expectedly absent in this group of patients leading to a more comfortable postop recovery.

The retroperitoneal technique also reduces the risk of intraperitoneal injury and leads to faster recovery of gastrointestinal function as was seen in our study too. ${ }^{22}$ It helps to resume early oral feeding and reduces risk of intestinal adhesion ${ }^{23}$ and is also beneficial for patients with the history of previous abdominal surgery. Retroperitoneal technique has less deleterious effect on ventilation and hemodynamic parameters that can be problematic with rising intra-abdominal pressure in transperitoneal approach. ${ }^{24}$ 
Reports in literature have shown the retroperitoneal approach has a shorter time to renal artery control ${ }^{25}$ which helps in early control of any major bleeding.

Single-site surgery usually requires special ports and angulated instruments which has actually limited the popularity of procedure due to higher costs and increased surgical difficulty. Most of the commercially available ports have a small opening in the abdominal wall which leads to clustering of instruments. Angulated instruments were devised to circumvent this but they increase the difficulty associated with this approach. The average size of retrieval incision in this series was $7 \mathrm{~cm}$ and the Alexis port assembly covered this incision and provided a wider space for motion of instruments. There was less fighting as the entry point of instruments being mobile, it provided a wider range of motion as compared to commercially available ports. No special instruments were required with this assembly and routine laparoscopic ports and instruments were used which has significant cost benefits to the patient over commercially available single ports.

Most of the previously described retroperitoneal techniques use balloon dilatation to create retroperitoneal space ${ }^{26,27}$ but with the translumbar approach, pneumoretroperitoneum could be reliably made under vision by using open surgical instruments.

There have been concerns about retroperitoneal approach to prolong the operative time in donor surgery and prolonged lateral positioning may lead to neural injuries. In our series, the time taken to completion in initial few cases was higher but the average of $170.3 \pm 52$ minutes compared favorably with transperitoneal cases at our center. The learning curve with retroperitoneal donor nephrectomy has been shown to be short in a retrospective review of 120 cases where operative times improved rapidly after performing 30 procedures. ${ }^{28}$ It has been shown in various studies that retroperitoneal approach leads to decreased operative time as time required to mobilize colon is saved and with a singlesite approach, time taken to place ports and later close them is avoided. $^{29}$

The homemade port assembly used in this series comprising of Alexis wound retractor with a surgical glove, is cost-effective and easy to use. The glove sustained the standard intra-abdominal pressure without any incidence of rupture. This assembly has been used in few other studies which have documented its effectiveness. ${ }^{30}$

\section{Limitations of Technique/Study}

There may be difficulty initially in approaching lumbar fascia through this incision for the inexperienced as it is not a popularly used approach. The working space is a bit limited as is any retroperitoneal approach but Alexis assembly with a glove adds to the space and is usually adequate unless the patient is small in size. The limitations of the study include early experience with a small sample size and that no comparison has been done with the standard transperitoneal approach. However, a randomized control trial is already underway at our center to assess the outcomes of this approach.

\section{Conclusion}

Single-site translumbar RPLDN is a feasible alternative approach to the donor surgery and can avoid the inherent risks associated with the transperitoneal technique. It has the potential to further reduce the pain associated with the donor nephrectomy operation.

\section{References}

1. Wolfe RA, Ashby VB, Milford EL, et al. Comparison of mortality in all patients on dialysis, patients on dialysis awaiting transplantation, and recipients of a first cadaveric transplant. N Engl J Med 1999;341(23):1725-1730.

2. Hariharan $\mathrm{S}$, Johnson $\mathrm{CP}$, Bresnahan $\mathrm{BA}$, et al. Improved graft survival after renal transplantation in the United States, 1988-1996. N Engl J Med 2000;342(9):605-612.

3. Ratner LE, Ciseck LJ, Moore RG, et al. Laparoscopic live donor nephrectomy. Transplantation 1995;60(9):1047-1049.

4. Nicholson ML, Elwell R, Kaushik M, et al. Health-related quality of life after living donor nephrectomy: a randomized controlled trial of laparoscopic vs open nephrectomy. Transplantation 2011;91:457-461.

5. Dunn JF, NylanderJr WA, Richie RE, et al. Living related kidney donors. A 14 year experience. Ann Surg 1986;203(6):637-643. DOI: 10.1097/00000658-198606000-00008.

6. Nanidis TG, Antcliffe D, Kokkinos C, et al. Laparoscopic vs open live donor nephrectomy in renal transplantation: a meta-analysis. Ann Surg 2008;247(1):58-70. DOI: 10.1097/SLA.0b013e318153fd13.

7. Greco F, Hoda MR, Alcaraz A, et al. Laparoscopic living-donor nephrectomy: analysis of the existing literature. Eur Urol 2010;58(4):498-509. DOI: 10.1016/j.eururo.2010.04.003.

8. Yang SC, Park DS, Lee DH, et al. Retroperitoneal endoscopic live donor nephrectomy: report of 3 cases. J Urol 1995;153(6):1884-1886. DOI: 10.1016/S0022-5347(01)67339-7.

9. Yagisawa $\mathrm{T}$, Amano $\mathrm{H}$, Ito $\mathrm{F}$, et al. Adrenal hemangioma removed by a retroperitoneoscopic procedure. Int J Urol 2001;8(8):457. DOI: 10.1046/j.1442-2042.2001.00352.x.

10. Gill IS, Uzzo RG, Hobart MG, et al. Laparoscopic retroperitoneal live donor nephrectomy for purpose of allotransplantation and autotransplantation. J Urol 2000;164(5):1500-1504. DOI: 10.1016/ S0022-5347(05)67015-2.

11. Flowers JL, Jacobs S, Cho E, et al. Comparison of open and laparoscopic live donor nephrectomy. Ann Surg 1997;226(4):483-489. DOI: 10.1097/00000658-199710000-00009.

12. London E, Rudich S, McVicar J, et al. Equivalent renal allograft function with Laparoscopic vs open live donor nephrectomy. Transplant Proc 1999;31(1-2):258-260. DOI: 10.1016/S0041-1345(98)01526-7.

13. Ratner LE, Kavoussi LR, Schulam PG, et al. Comparison of laparoscopic live donor nephrectomy vs the standard open approach. Transplant Proc 1997;29(1-2):138-139. DOI: 10.1016/S0041-1345(96)00037-1.

14. Merlin TL, Scott DF, Rao MM, et al. The safety and efficacy of laparoscopic live donor nephrectomy: a systematic review. Transplantation 2000;70(12):1659-1666. DOI: 10.1097/00007890200012270-00001.

15. Ryu DS, Park WJ, Oh TH. Retroperitoneal laparoendoscopic singlesite surgery in urology: initial experience. J Endourol 2009;23(11): 1857-1862. DOI: 10.1089/end.2009.0254.

16. Pansadoro V. The posterior lumbotomy. BJU Int 2005;95(7):1121-1131. DOI: 10.1111/j.1464-410X.2005.05483.x.

17. Raman JD, Bensalah K, Bagrodia A, et al. Laboratory and clinical development of single keyhole umbilical nephrectomy. Urology 2007;70(6):1039-1042. DOI: 10.1016/j.urology.2007.10.001.

18. Raman JD, Bagrodia A, Cadeddu JA. Single incision, umbilical laparoscopic vs conventional laparoscopic nephrectomy: a comparison of perioperative outcomes and short term measures of convalescence. Eur Urol 2009;55(5):1198-1204. DOI: 10.1016/ j.eururo.2008.08.019.

19. Andonian S, Rais-Bahrami S, Atalla MA, et al. Laparoendoscopic singlesite Pfannenstiel vs standard Laparoscopic donor nephrectomy. J Endourol 2010;24(3):429-432. DOI: 10.1089/end.2009.0185.

20. Canes D, Berger A, Aron M, et al. Laparo-endoscopic single site (LESS) vs standard laparoscopic left donor nephrectomy: matched-pair comparison. Eur Urol 2010;57(1):95-101. DOI: 10.1016/ j.eururo.2009.07.023.

21. Gupta A, Ahmed K, Kynaston HG, et al. Laparoendoscopic singlesite donor nephrectomy (LESS-DN) vs standard laparoscopic donor 
nephrectomy. Cochrane Database Syst Rev 2016;2016(5):CD010850. DOI: 10.1002/14651858.CD010850.pub2.

22. Zhu H, Shen C, Li X, et al. Laparoscopic pyeloplasty: a comparison between the transperitoneal and retroperitoneal approach during the learning curve. Urol Int 2013;90(2):130-135. DOI: 10.1159/ 000343989.

23. Fan $\mathrm{X}, \mathrm{Xu} \mathrm{K}$, Lin $\mathrm{T}$, et al. Comparison of transperitoneal and retroperitoneal laparoscopic nephrectomy for renal cell carcinoma: a systematic review and meta-analysis. BJU Int 2013;111(4):611-621. DOI: 10.1111/j.1464-410X.2012.11598.x.

24. Nadu A, Ekstein P, Szold A, et al. Ventilatory and hemodynamic changes during retroperitoneal and transperitoneal laparoscopic nephrectomy: a prospective real-time comparison. J Urol 2005;174(3):1013-1017. DOI: 10.1097/01.ju.0000169456.00399.de.

25. Kihara K. Application of gasless laparoendoscopic single port surgery, gasless, to partial nephrectomy for renal cell carcinoma: gasless-clampless partial nephrectomy as a multiply satisfactory method. Int J Urol 2012;19(1):3-4. DOI: 10.1111/j.1442-2042.2011. 02881.x.
26. Bachmann A, Wolff $T$, Ruszat R, et al. Retroperitoneoscopic donor nephrectomy: a retrospective, non-randomized comparison of early complications, donor and recipient outcome with the standard open approach. Eur Urol 2005;48(1):90. DOI: 10.1016/j.eururo.2005.03.007.

27. Tanabe $\mathrm{K}$, Miyamoto $\mathrm{N}$, Ishida $\mathrm{H}$, et al. Retroperitoneoscopic live donor nephrectomy (RPLDN): establishment and initial experience of RPLDN at a single center. Am J Transplant 2005;5(4 Pt 1):739. DOI: 10.1111/j.1600-6143.2004.00702.x.

28. Tokodai K, Takayama T, Amada N, et al. Retroperitoneoscopic living donor nephrectomy: short learning curve and our original hybrid technique. Urology 2013;82(5):1054-1058. DOI: 10.1016/ j.urology.2013.08.003.

29. Desai MM, Strzempkowski B, Matin SF, et al. Prospective randomized comparison of transperitoneal vs retroperitoneal laparoscopic radical nephrectomy. J Urol 2005;173(1):38-41. DOI: 10.1097/01. ju.0000145886.26719.73.

30. Sharma A, Singh S, Kumar S, et al. Single-incision laparoscopic donor nephrectomy: an initial experience. Saudi J Kidney Dis Transpl 2012;23(3):581-584. 